Intermedia International e-Journal, Fall -December - 2017 4(7)

*DOI NO: 10.21645/intermedia.2017.40 *Submit Date: 01.12.2017＊Acceptance Date: 21.12.2017 *ISSN: 2149-3669

\title{
Yeni Medyada Troller Ve Trollük Kültürü
}

\section{Trolls In The New Media And The Trolling Culture}

\author{
Ayşe Büşra Yılmaz ${ }^{1}$ \\ İstanbul Ticaret Üniversitesi, Iletişim Fakültesi \\ Medya İletişim Sistemleri, \\ İstanbul-Türkiye \\ Cem Işıkdoğan ${ }^{2}$ \\ İstanbul Ticaret Üniversitesi, İletişim Fakültesi \\ Medya Illetişim Sistemleri, \\ İstanbul-Türkiye
}

\begin{abstract}
Özet: İnsanlık tarihinin en başından beri var olan iletişim, süreç içerisinde farklı bir boyuta evrimleşmiştir. Hızla değişen ve yenilenen teknoloji, bireylerin istek, sorun ve ihtiyaçlarına yanıt verir şekilde iletişim araçlarının gelişmesine neden olmuştur. Gelişen bu iletişim araçları, internet ve sosyal medya, gün geçtikçe daha da popüler olmuş; mobil telefon kullanımının artması ile hayatımızın her alanına girmiştir. Bireyler süreç içerisinde bu iletişim araçlarını daha yoğun kullandıkça farklı olanak ve iletişim fırsatlarını keşfetmeye başlamışlardır. Geleneksel kitle iletişim araçları, gazeteler, dergiler ve televizyon, bireylere duyurulacak haberlerin, yani bilgi akışının, tek yönlü olduğu iletişim ortamlarıdır. Bireyler onlara sunulan haber, eğlence, video gibi içerikleri tüketir, etkileşim kuramaz ve kendi içeriklerini üretemezler. Üreticiler ve tüketiciler farklı bireylerdir. Yani bireysel kişiler, geleneksel kitle iletişim araçlarında yalnızca tüketiciyken gelişen teknoloji ile internet ve sosyal medyada hem tüketici hem üretici konumuna geçmişlerdir.
\end{abstract}

Sosyal medyadaki üretici ve tüketici sayısı gün geçtikçe artmakta, sosyal medya kullanımının etki ettiği alan hızla genişlemekte ve bilgi alma süresi ise yeni sosyal medya araçlarıyla kısalmaktadır. Sosyal medya ilk olarak teknoloji ile ilgilenen bireyler tarafından kullanılsa da sosyal medyaya her geçen gün yeni kişiler dahil olmaktadırlar. İnternette yeni çıkan uygulamalar ve yeni sosyal medya araçları, kişiler arasında kulaktan kulağa yayılmakta ve yeni medya düzeninde yer almak isteyen kişiler tarafından kullanılmaktadırlar. Bu durum, sosyal medyanın etki ettiği alanın da hızla genişlemesini sağlamaktadır. Sosyal medyaya ilk olarak tüketici olarak katılan kişilerin bazıları, üretici konumuna geçmekte ve bu yeni katılan üreticiler de kendilerine özgün bir şekilde yeni konuları ele almaktadırlar. Yeni üreticiler yeni tüketiciler getirmekte ve bunun sonucu olarak, kişilerin sosyal medyaya katılımı giderek daha hızlı bir şekilde artmaktadır.

İletişim teknolojilerinin gelişmesi, sosyal medya kullanımı ve kullanıcıların yaratıcı içerikler paylaşması doğru orantılı bir şekilde artmıştır. Türkiye'de Twitter, yaratıcı yazıların ve görsellerin birlikte paylaşıldığı en önemli mecralardan biridir. Trollük, sosyal medya mecralarında yani bilgisayar ve internet teknolojisinin kullanıldığı çevrimiçi ortamlarda gerçekleşmektedir. Trol içerikler, gelecekte olması beklenen, eskiden veya şimdi kendine gündemde yer bulan bir konu ile ilgili abartı yorumların katılması, tepki çekmek amacıyla oluşturulan mesaj içerikli paylaşımlardır. İnternet trolleri, mizahi, dikkat çekici ve alaycı bir üslup ile içerik oluşturan bireylerdir. Trollerin bu şekilde rahatça içerik üretebilmesinin en önemli nedenlerinden biri ise internet ortamının sağladığı anonim kalma ayrıcalı̆̆ıdır.

\footnotetext{
${ }^{1}$ aysebusrayilmaz@gmail.com

2 cem1052@gmail.com
} 
Yapılan bu çalışmada, trollük kültürünün incelemeleri ve izleyicilerin bu kültürü yakından takip edip, katılımın git gide çoğaldığı iddia edilmektedir. Çalışmanın içeriğinde, Twitter'da belirlenen 13 fenomen trol hesap üzerinde tematik söylem analizi uygulanmıştır. Yapılan analizde trollerin mizahlarını yaratıcı dil ile bir araya getirip ürettikleri içerikler ortaya konulmuştur.

Çalışma sonucunda, Türkiye'de bulunan Twitter trollerinin kendilerine ait mizahi, yaratıcı dilini uygun buldukları olaylar ile kullanıp; dolaşıma soktukları ve izleyicilerden yoğun ilgi gördükleri saptanmıştır. Böylelikle, fenomen olan Twitter trolleri, gelişen teknoloji ile yeni medya içerisinde, trol kültürünün yayılmasına ve katılımın artmasına katkı sağlamaktadırlar.

Anahtar Kelimeler: Trollük kültürü, Trollük, Twitter, Caps, Yaratıcı Dil Kullanımı

Extended Abstract: The communication, which has existed since the beginning of history, has evolved into a different dimension. Rapidly changing and renewed technology has led to the development of communication tools that respond to the wishes, demands and needs of individuals. These emerging communication tools, internet and social media, become more popular as time goes by. Besides, with the increasing use of mobile phones, they have entered every area of our lives. Individuals have begun to explore different chances and communication opportunities as they use these communication tools more intensely in the process. Traditional mass media, including newspapers, magazines and television, are communication tools in which the information flows one way. Individuals can consume news, entertainment or videos, which are presented to them. For all that, they can't interfere with or produce content. Producers and consumers are different individuals. In other words, while individuals were only consumers in the traditional mass media, they became both consumers and producers within internet and social media.

The number of producers and consumers in social media is increasing, the coverage of social media is expanding and the information receiving time is shortening with new tools. Although social media is used by individuals who are interested in technology firstly, new people are included day by day. New applications and social media tools are spreading among people, and used by people who want to take part in new media format. This provides rapid expansion of the social media's impact area. Some of the people who first joined the social media as consumers become producers, and these newcomers take on new issues in their own way. New producers are bringing new consumers, and as a result, the participation of people in the social media is increasing.

The development of communication technologies, the use of social media and the sharing of creative content have increased similarly. Twitter in Turkey is one of the most important tools in which creative writings and visuals are shared. Trolling takes place in social media circles, that are the online environments where computer and Internet technology are used. Troll contents are the message-sharings that are expected to happen in the future, involving exaggerated comments on a subject that has been on the agenda in the past or now, and are intended to react. Internet trolls are individuals who create content with a humorous, cynical and sarcastic style. One of the most important reasons why trolls can easily produce content in this way is the anonymous staying privilege provided by the internet environment.

Development of communication technologies, social media usage and creative content shares by users have been increasing correlatively. Twitter is one of the most significant platforms, in which creative contents and images are shared together, in Turkey. In this study, trolling culture is examined; and it is claimed that number of users who are following this culture is increasing and participation is rising. Thematic discourse analysis is used on 10 Twitter celebrity trolls, in the content of this study. Contents, which are created by trolls with their own creative style, are showed in the analysis.

As a result of this study, it is determined that Twitter trolls in Turkey spread the contents, which they find suitable to their personal humorous and creative language, and get great attention from users. Thus, celebrity Twitter trolls are spreading the troll culture and increasing the participation in the new media thanks to developing technology.

Key Words: Trolling culture, Trolling, Twitter, Caps, Creative Language Usage 


\section{Giriş}

Sosyal medya kavramı üzerine birçok tanım mevcuttur. Evrensel olarak bir tanımı olmayan sosyal medya kavramında yaşanılan ilk gelişme Web. 2.0 teknolojisidir. Sosyal medya; Web 2.0 teknolojisi üzerine kurulan, kişiye özel, kullanımı kolay, sosyalleşmeyi öne çıkaran, etkileşim sağlayan, grupların oluşmasına imkan tanıyan bir sistemdir (Bruns ve Bahnisch, 2009:7). Sosyal medya, toplumda yer alan birçok kullanıcının paylaşım yaptığı ve geri bildirim aldığı, kullanıcı müdahalesine açık sanal bir ortamdır. Sürekli güncelliğini koruyan sosyal medya, sosyal paylaşıma ve birden fazla kişinin kullanımına imkan tanımaktadır. İnsanların, fikirlerini ve yaratıcı dillerini rahatça ortaya koymasını sağlayan sosyal medya, firmaların da varlığını gösterdikleri stratejik bir alan olarak da değerlendirilebilir (Bat ve Vural, 2014: 101).

Web 1.0 internet teknolojisinin tek yönlü, kullanıcıların pasif izleyici olan yapısı; Web 2.0 ile iki yönlü, dinamik hale gelmiştir. Web 2.0 kullanıcıların içeriklere katkıda bulunmalarına ve içerik oluşturmalarına imkan sağlamış ve bireylerin tercihlerini ön planda tutmuş; interneti, etkileşim ve katılıma dayalı bir ortam haline getirmiştir (Bat ve Vural, 2014: 106). Haber kanallarının bulunduğu sosyal medya, interaktif ve dinamik formlarda olup kullanıcıların bilgiye erişimini sağlamış; aynı zamanda kullanıcıların konu ile ilgili görüş ve fikirlerini alan bir platform haline gelmiştir. Bireyler tercih ettikleri konu ile ilgili yorumlarını veya karşıt görüşlerini sunabilmekte, kendi sosyal mecralarında (Facebook, Twitter) konuyu tartışmaya açabilmektedir.

Internet teknolojisinin Web 1.0'dan 2.0'a geçmesi ile birlikte, kullanıcılar da kendini ifade etmeye ve açlı̆ını tatmin edebilmek için sosyal medyayı aktif olarak kullanmaya başlamışlardır. Sosyal medyanın kullanıcılara mutluluk vadetmesi kişileri arayışa sürüklemiştir. Yaratıcı dil kullanan bireyler, geleneksel medyada kendilerini ifade etme fırsatı bulamamışlardır. Sosyal medyanın ortaya çıkması ile birlikte bu yaratıcı dil ve mizah açığa çıkmaya ve kitlelere yayılmaya başlamıştır. Sosyal medya kişilere olumlu duygular ve haz dışında, olumsuz duygular da vermektedir. Kullanıcılar savunma psikolojisi ile diğer kullanıcılara ve güncel olaylara saldırabilmektedir. Hazzın kaynağı olarak görülen yaratıcı dil yani mizahın dışa vurumu Capslerdir (Kullar ve İnci, 2015).

Bu noktada bireylerin kendilerini dilediği gibi ifade ettikleri katılımcı kültür olgusu ortaya çıkmaktadır. İletişim teknolojileri gelişerek katılımcı kültürü bir üst seviyeye taşımakta, yaratıcı dilin aktif bir şekilde kullanılmasını ve yayılmasını sağlamaktadır. Yaratıcı ve pratik dilin nasıl oluşturulduğu Twitter trollerinin Tweetleri yani içerikleri incelenerek görülebilir.

\section{Yöntem}

Yapılan çalışmada Twitter üzerinden belirlenen 20 trol hesaba tematik söylem analizi (Potter ve Wetherell, 1987; Burman ve Parker, 1993) uygulanmıştır. Bu analiz ile, incelenen trol hesapların kullandığı dil ve bu trollerin paylaşımları ortaya konmuştur. Araştırma kapsamında belirlenen trol hesapların tespiti için ilk olarak profesyonel tarafta Dijital Medya Ajansı, Nüans Illetişim Ajansı'ndan liste alınmıştır. İkinci olarak beş farklı sosyal girişimin çalışanlarının trol hesap olduğunu düşündüğü Twitter kullanıcılarının listelenmesi istenmiştir. İki şekilde veri toplanmasının ardından, hesaplar incelenmiş ve tematik içerik analizi için 20 hesap örneklem olarak kullanılmıştır.

1. napıyosun tugay @kacamayankacak

2. Buraking Bad @burak32

3. TAKO @taylanozmutlu

4. Archie Gaviria @archiegavi

5. Buse Karasu @aynenhe

6. yungblud @ohnodogg 


\section{Serhat W. @brudermartin}

8. bayram oğlu emre @emrekosapinar

9. Kaan Kayabalı @kkaank

10. gizem @oteberi

11. İsviçreli @bilim_adami

12. Komutan Logar @_KomutanLogar

13. Üniversite Öğrencisi @mayorofcampus

14. Muhammet Çiçek @muhammet_ciceek

15. Ressam Bob @RessamBob

16. Esmow @eslimtesliim

17. Ezel @thepirenses

18. Hilal @_ebonit

19. ümit + @ilgincbisey

20. Önder Şeren @onderseren

Listelenen tüm hesaplar, dijital ortamda herkesin okuyabileceği, erişebileceği anonim veyahut yarı anonim kimliklerdir. Seçilen bu hesapların siyasi, toplumu kışkırtacak, nefret dolu içerikler içermeyen nitelikte olmasına özen gösterilmiş; mizahi içerik kullanan hesaplar incelenmiştir.

\section{Yeni Medya}

Yeni iletişim teknolojilerinin gelişmesi ile birlikte, kullanıcıların zaman ve mekan bağımsı olarak etkileşim kurdukları sanal ortama yeni medya adı verilir. Yeni medyanın geleneksel medyadan en büyük farkı olan bu özelliği, kullanıcıların iletişim sürecindeki alışkanlıklarını çeşitli şekillerde etkilemektedir. 1980'li yıllarda bilgisayar ve 1990'lı yıllarda internetin toplum hayatına girmesiyle medya kavramında devrim meydana gelmiş ve yeni medya kavramı ortaya çıkmıştır. Bilgisayar ve internetten önce kullanılan geleneksel medyanın, bu gelişmeler sonucunda önemi giderek azalmış; geleneksel medya yeni teknoloji karşısında daha az tercih edilen bir konuma gelmiştir. Thompson'a göre yeni medya, bilgi teknolojisi ile kapsamı genişlemiş, zamanla kullanımı kolaylaşmış ve yapabilirliği artmış iletişim araçlarıdır (Derya Yücel, 2012). McLuhan, gerçek devrimin, kişisel ve toplumsal yaşamın, yeni teknolojiye uyarlandığını ve medyanın da bu şekilde adapte olduğunu iddia etmektedir (McLuhan,2014). Tüm medya çeşitleri bir gün yeni medyaya dönüşecektir. Bugün yapılan eski ile yeni ayrımı geçicidir. Televizyon örneğinden yola çıkarsak "eski" iletişim aracının "yeni” iletişim aracına dönüşümünü gözlemleyebiliriz (Jakubowicz,2009). Yeni medyanın geleneksel medyadan en önemli farklarından biri de kullanıcıların yeni medya araçlarına katılım gösterebilmesi ve yeni medya araçlarında kullanıcılar tarafından içerik üretilebilmesi olarak tanımlanmaktadır (Dovey, Giddings, Grant, Kelly ve Lister; 2009). Manovich ise yeni medya araçlarının en önemli farkı olarak; tüm içeriklerin matematiksel olarak tanımlanabilir ve algoritmalar ile manipüle edilebilir olduğunu belirtmekte ve medyanın bu sayede, programlanabilir bir hale geldiğini iddia etmektedir (Manovich, 2001).

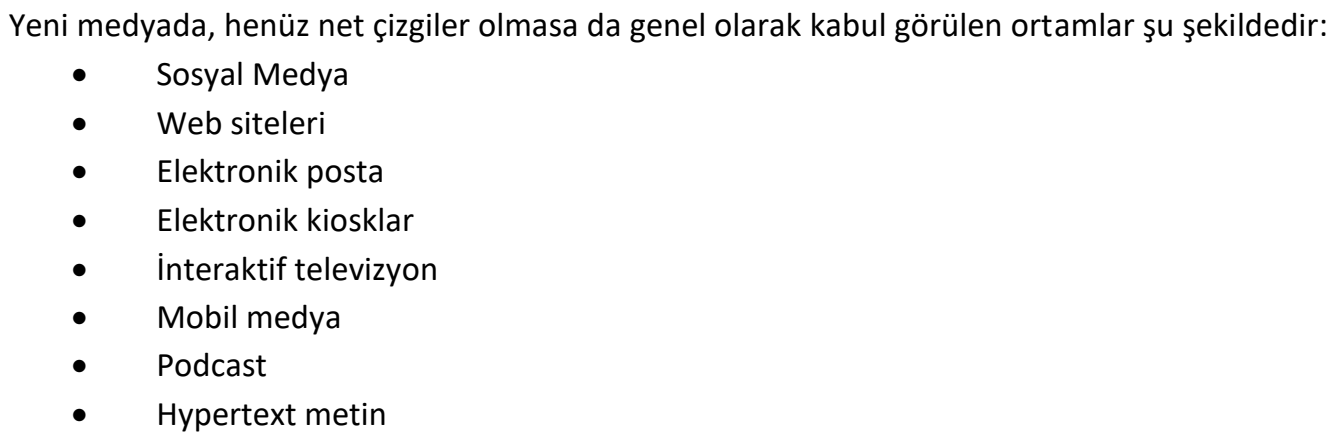


- Blog

- Sanal gerçeklik

- Bilgisayar oyunları

- Multimedya (Ses, Video, Animasyon vb.)

- Yazılım

\section{Twitter ve Twitter'ın Yapısı}

Twitter gün geçtikçe kullanıcı sayısında artış yaşayan Web 2.0 teknolojilerinden biridir. Twitter en önemli mikroblog sitelerindendir. Kullanıcılar bu sosyal mecradan takip etmek istedikleri kişileri ekleyerek yeni bir ağ oluşturabilirler (Greenhow, 2009). Twitter kullanıcıları, 140 karakter ile duygu, düşünce, resim, video gibi içerikleri paylaşabilir; başka kullanıcıların paylaşımlarına yorum yazabilirler. Düşünce aktarımlarının 140 karakterle sınırlı olması ve ağ içerisinde yayılması, Twitter’ın sosyal ağ özelliğini göstermektedir. Twitter 2006 yılında teknoloji girişimcileri olan Evan Williams, Jack Dorsey ve Biz Stone tarafından geliştirilmiştir ve internet üzerinden SMS (kısa mesaj) olarak ortaya çıkmıştır. Diğer mikrobloglara göre iletişim ortamı daha güçlü ve ara yüzü basittir. Twitter, açık ifade özelliği ile içerik oluşturmayı kolay hale getirmiştir (Altunay, 2010; O’ Reilly ve Milstein, 2009).

Twitter'da “@” (Mention) ile kullanıcı başka kullanıcılara referans verebilir, “RT” (Retweet) ile diğer kullanıcılarının Twitter içeriklerini paylaşabilir, "\#” (Hashtag) ile belli bir konu başlığı altında içerikler gruplanabilmektedir. Twitter ana sayfasında bulunan "Trendy Topic"ler (TT) Hashtaglerle belirlenir. Hashtagler, dikkat çekilmek istenen konuya, kamuoyunu yönlendirmek için kullanılan uygulamalardır. Twitter'da "kalpler", kullanıcıların beğendiği içerikler, "sabitlenen gönderi" ise kişilerin paylaştığı içeriklerin en başına koyduğu gönderilerdir. Twitter'da hesabın içeriğinin başkaları tarafından görünmesini engelleyen bir gizlilik ayarı da bulunmaktadır. Hesap gizli ise hesap sahibinin Tweetlerine yani paylaştığı içeriklere erişilememektedir.

\section{Trollük Nedir?}

Yeni medyada sıklıkla rastlanan sözcüklerden biri troldür. Türk Dil Kurumu (TDK, 2015) tarafından trolün anlamı "Teknelerle suyun dibinde sürüklenerek çekilen, huni biçiminde geniş ağızlı balık ağı" olarak tanımlanmıştır. Trol sözcüğü, internet ortamında izleyicilerin dikkatini çeken ve yarattığı içerikler ile gündemde olmaya çalışan kişiler anlamına gelir. Troller internet ortamında içerik üretir, içerikleri dolaşıma sokar ve sonraki süreçte bilinçli olarak muhalif ve saldırgan düşünce yapısında olurlar diyebiliriz (Hardaker, 2013). Bu davranışların çoğu eğlence amacı ile gerçekleşmektedir. Trollerin birçoğu provokatif, küfürlü, cinsiyetçi, ırkçı, alevlendirici ve yıkıcı bir yazım biçimini tercih etmektedir (Özsoy, 2015). Trollük, sosyal ağlar ya da forumlar gibi çevrimiçi ortamlarda gerçekleşmektedir. Trol davranışlar, bir kesimin dikkatini çekmek amacıyla absürt, kasıtlı olarak yanlış ve kışkırtıcı içerik paylaşmayı kapsamaktadır. Kısaca troller, absürt, eğlenceli veya olumsuz, yıkıcı bir davranış modelini benimseyip dikkat çekmek amacıyla hareket eden bireylerdir.

Trollük, internet ortamında farklı biçimlerde görülmektedir. Bir mikroblog sitesi olan Twitter'da trollerin başlattığı konuşmalara diğer trollerin de katılması ile hedef belirlenen konu ile ilgili eğlence amaçlı Tweetler atılmaktadır. (Özsoy, 2015).

Taiwo (2014), iki tür trolden söz etmektedir. İlki tartışmayı başlatan troller, ikincisi ise başkalarının paylaşımlarına yönelik yorum yapan trollerdir. Twitter'da incelenen 20 trol hesapta; profil ve kapak fotoğraflarında yaratıcı, dikkat çekici görseller kullandıkları görülmüştür. 


\section{Caps Nedir?}

Sosyal medya, erişilebilirlik ve yenilik özellikleri ile kullanıcıların kendini ifade edeceği ortam haline gelmiştir. Dünya üzerinde milyonlarca kullanıcısı bulunan sosyal medya, herkesin kendi kitlesini yaratmasına olanak sağlar. Geleneksel medyada, o alanda uzmanlaşmış kişilerin içerik üretmesi gerekirken, sosyal medyada herkes içerik üretimine katkıda bulunabilir (Vural ve Bat, 2010: 3352). Ülkemizde gençlerin sosyal medya üzerinden paylaştığı içeriklerin büyük bir kısmını "Caps” yani “Capture” oluşturur (Langenscheidt, 2010). "Caps” kelimesi, ekranda olan olayların videosunu veya ekran görüntüsünü komik bir şekilde ifade etmek için kullanılmaktadır. Ülkemizde Capsler ilk olarak İnci Sözlük sitesinde kullanılmaya başlanmış, sonrasında ise tüm sosyal medya mecralarına yayılmıştır. Capsler, izlenilen bir film karesinden, eski bir resim tablosundan veya televizyon programlarından alınarak üzerine mizahi yazıların gelmesi ile ortaya çıkmaktadır. Bu nedenle Capslerin içerikleri genel olarak sosyal içerikli olaylardan oluşmaktadır. Capslerin çeşitli şekilleri bulunmaktadır. Hızla tüm sosyal medya mecralara yayılan Capslerde, içeriklerdeki resimlerin üzerinde veya alt kısmında yaratıcı, mizahi bir yazı bulunmaktadır. Yazıların görsel ile bağlantılı olması zorunda değildir. Üretilen Capsler bireysel olarak sosyal medyada dolaşıma sokulabilmektedir.

\section{Türkiye'deki Twitter Trollerinin Yaratıcı İçerik Üretimleri}

Eğlenceli içerik paylaşımı yapan troller, Türkiye gündemini oluşturan veya gündemi kendilerinin oluşturacakları konularla ilgili yaratıcı dil kullanarak Caps üretimi yapmaktadırlar. Üreticilerin takipçileri ile paylaştıkları içerikler, üreticinin mizahı ve tespitleri ile harmanlanmaktadır. Gündemde olan olayların troller tarafından tespit edilip yaratıcı dil kullanarak okuyuculara sunması, okuyucuların beğenisi ve diğer kişilerin de paylaşması ile binlerce kişiye ulaşmaktadır.

Çalışmanın bu bölümünde, trollerin Twitter'da yaratıcı dil ve mizahı aktif olarak kullandığı “Nusret'in tuz serpmesi" olayı incelenmiştir. Bu içeriğin incelenmesinin en önemli nedeni herkesin konuya mizah ekleyerek çoğalttığı, hızlıca tüketilen, dünyada yankı bulan bir içerik olmasıdır.

Resim 1: Caps Örneği 1

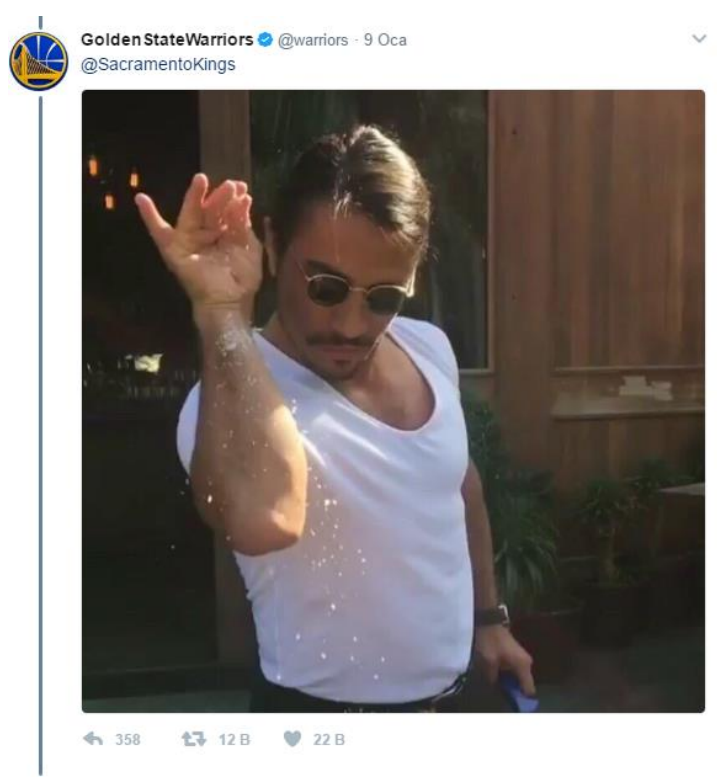

Nusret'in et yaparken paylaştığı videolar trollerin dikkatini çekmiş ve mizahi içerikler \#saltbae etiketi ile ilk olarak 9 Ocak 2017'de Amerika Basketbol ligi takımlarından Golden State Warriors tarafından Twitter'da 
paylaşılmıştır. İngilizcede 'Salt' tuz anlamına geliyor. Baby kelimesinin kısaltması olan BAE ise daha çok 'Before anyting else'in kısaltması olarak 'Herkesten önce gelen' anlamında kullanılıyor (“Et Restoranı Sahibi”, 2017).

Warriors hesabı, maçın özetini atarak "Sacramento Kings'i geriden gelip yendiğimiz maçın özetini izleyin" yazdı. Sacramento Kings de bu Tweet'e, "Hayır" cevabını verince, Warriors'ın yanıtı Nusret Gökçe'nin Amerika'da meşhur olan fotoğrafıyla oldu (“Amerika'yı da Salladı", 2017). Görsel ve yazının bir arada kullanılması ile oluşturulan bu Caps 12 bin Retweet, 22 bin beğeni almış ve büyük bir kitlenin ilgisini çekmeyi ve \#saltbae akımının yayıımasını sağlamıştır.

Resim 2: Caps Örneği 2

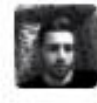

napiyosun tugay

@kacamayankacak

2- Takip et $\checkmark$

Ve yollar açılır.. \#saltbae

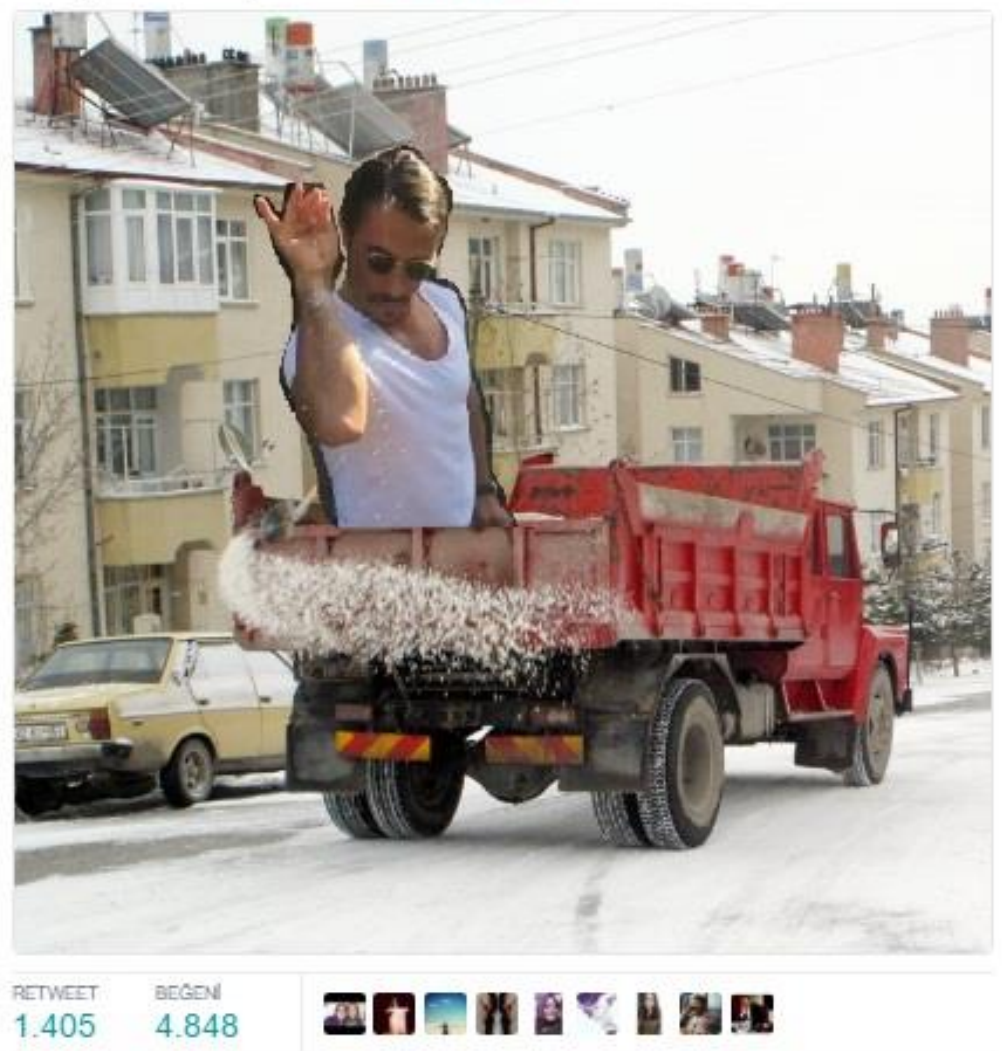

$02: 32-09$ Oca 2017

4 10 t? $1405 \div 4848$

Golden State Warriors'un attığı Tweet sonrası izleyicilerin yoğun ilgi göstermesi sonucu @kacamayankacak adlı Twitter trolü Nusret'in tuz serpme hareketi ile ilgili paylaştığı Caps ile 1.405 Retweet, 4.848 beğeni alarak yoğun ilgi görmüştür. İstanbul genelinde yoğun kar yağışı olmasını ve ara sokaklardaki tuzlama çalışmalarının yetersiz kalmasını, Nusret'in fenomen olan tuzlama hareketi ile birleştirip, yaratıcı bir dille oluşturulmuş Caps ile dolaşıma sokulduğunu görmekteyiz. Diğer sosyal medya mecralarında da paylaşılan bu Caps, yaratıcı ve mizahi içeriklerin ne kadar hızlı yayıldığını göstermektedir. 


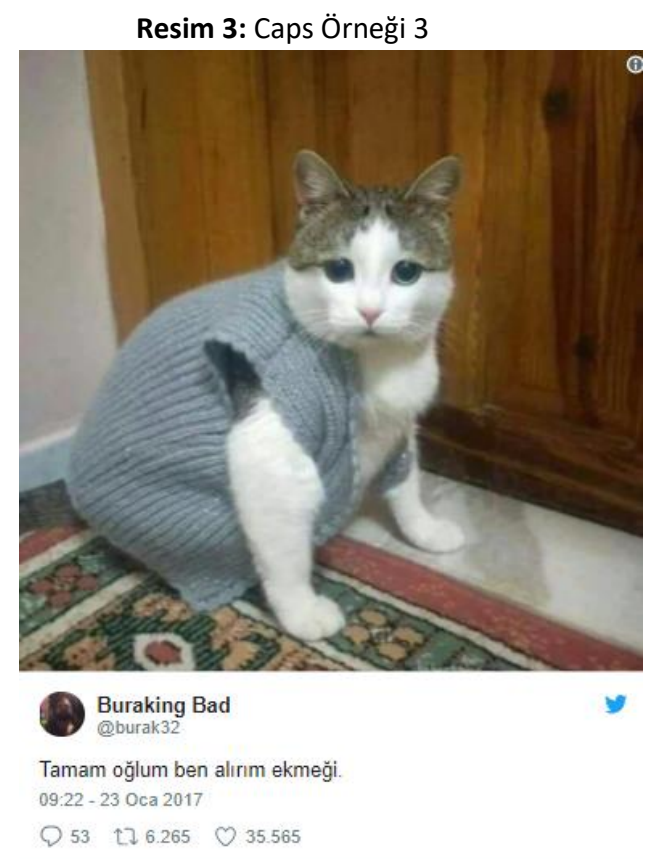

Türkiye'deki bazı troller, geleneksel değerlerimizi mizahi bir dille kullanarak içerikler üretmektedirler. Kısaca, ülkemizde herhangi bir yerde denk gelebileceğimiz fotoğrafları Capslere dönüştürmektedirler. Bu Capsleri yaratmak için kendileri fotoğraf çekmekte veya internette karşılaştıkları fotoğrafları kullanmaktadırlar. $\mathrm{Bu}$ fotoğrafların profesyonel şekilde çekilmiş olmasına gerek yoktur. Geleneklerimizi yansıtması ve mizahi olarak kullanılabilmesi yeterlidir. Twitter trolü "Buraking Bad” amatör bir şekilde çekilen, kazak giydirilmiş bir kedi fotoğrafını, çocuklarına herhangi bir iş yaptırmak isteyen Türkiye'deki bir aile büyüğü rolü ile bağdaştırarak yukarıdaki Caps'i hazırlamıştır. Trolün Twitter'da paylaştığı bu içerik 53 yorum, 6.265 retweet ve 35.565 beğeni almıştır.

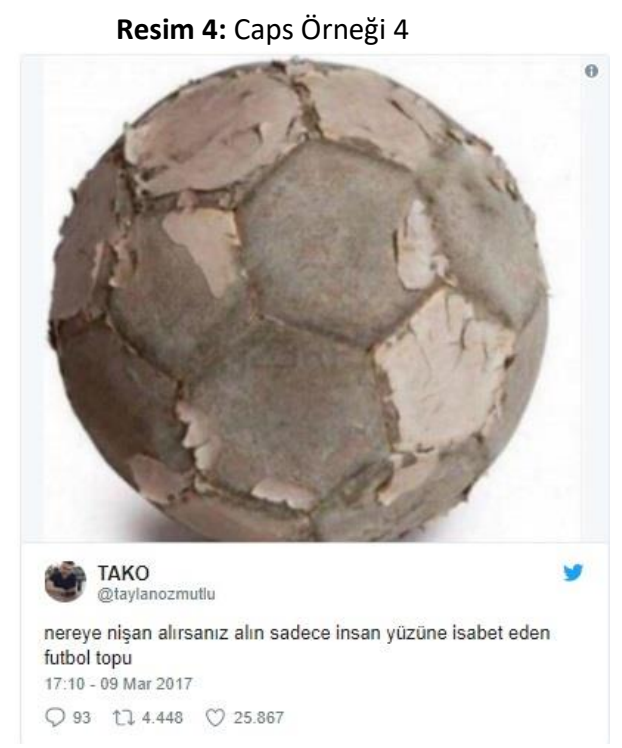

Türkiye'deki trol kültürüne etki eden bir konu da Türkiye'nin 90'lar dönemi olmuştur. 90'larda çocukluk dönemi yaşayan sosyal medya kullanıcıları, bu konuda hem üretici hem tüketici konumundadırlar. Türkiye'de 
90’larda ünlü olan kişiler, filmler, diziler, şirketler ve ürünler bu tarz Capslerin parçaları olmaktadırlar. Bu Capslerdeki hedef o dönemde yaşamış kişilere, ilgili konular çerçevesinde, o dönemki komik deneyimlerini hatırlatıp kişileri gülümsetebilmektir. Bu tarz Capslere "TAKO" isimli trol tarafından oluşturulan yukarıdaki içerik örnek olarak verilebilir. Bu kullanıcı, sadece bir ürün görselini kullanıp o dönemki komik bir deneyimini paylaşarak Twitter'da 93 yorum, 4.448 retweet ve 25.867 beğeni alabilmiştir.

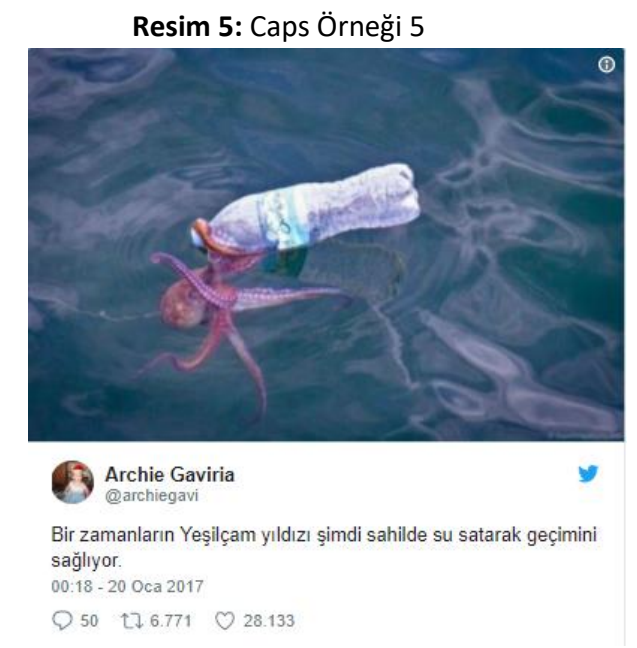

Sosyal medya araçlarının olmadığı ve geleneksel medyanın yoğun olarak kullanıldığı dönemde, televizyon en popüler iletişim araçlarından biri olmuştur. Televizyonda yayınlanan diziler, filmler, programlar çocuk-büyük birçok kişi tarafından izlenmiş; özellikle Yeşilçam sineması günümüz Türkiye’sinde hala konuşulmaktadır. @archiehavi isimli Twitter trolü tarafından, içinde bir ahtapot ve pet şişe olan bir fotoğraf karesi ile hazırlanmış yukarıdaki Caps, Yeşilçam'ın en ünlü fantastik filmlerinden "Tarkan: Viking Kanı" filminin ünlü ahtapot sahnesine benzetilerek Twitter'da paylaşılmıştır. Bu paylaşım mizahi bir dille günümüze uyarlanmış ve Twitter'da 50 yorum, 6.771 Retweet ve 28.133 beğeni almıştır.

Resim 6: Caps Örneği 6

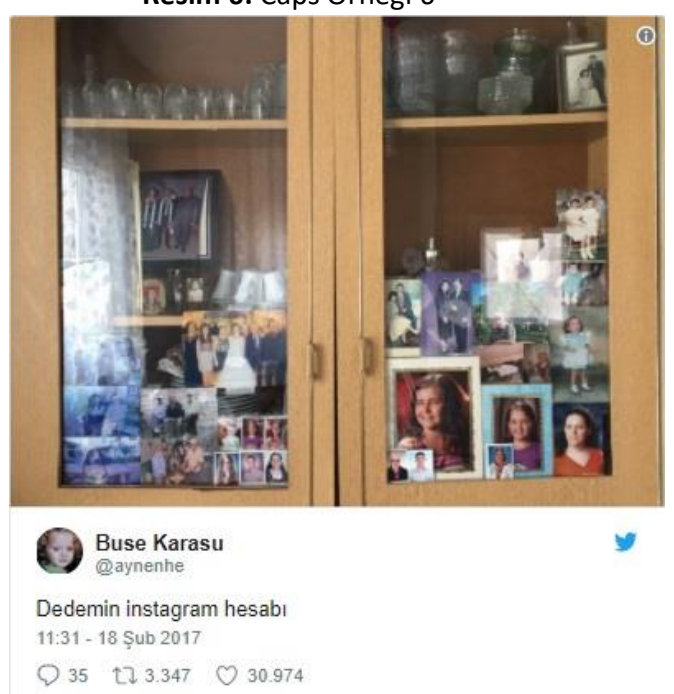

Twitter trollerinin en çok üzerinde konuştuğu konulardan biri de farklı yaş gruplarındaki bireylerin günlük alışkanlıkları olmaktadır. O yaş grubundaki kişilere çok normal gelen bu günlük alışkanlıklar, trollere ve trollerin takipçi kitlelerine farklı ve komik gelebilmektedir. Troller, gün içerisinde bu tarz herhangi bir alışkanlık ile denk 
geldiklerinde o kareyi kaydedip mizahi ve takipçilerine uygun bir dil ile harmanlayarak Caps haline getirirler. Twitter trolü @aynenhe, kendinden yaşça büyük bir kişi tarafından birçok fotoğrafın saklandığı bir dolabı fotoğraf paylaşımı uygulaması Instagram ile bağdaştırarak yukarıdaki içeriği üretmiştir. Twitter'da yayınladığı bu Caps 35 yorum, 3.347 Retweet ve 30.974 beğeni almıştır.

Resim 7: Caps Örneği 7

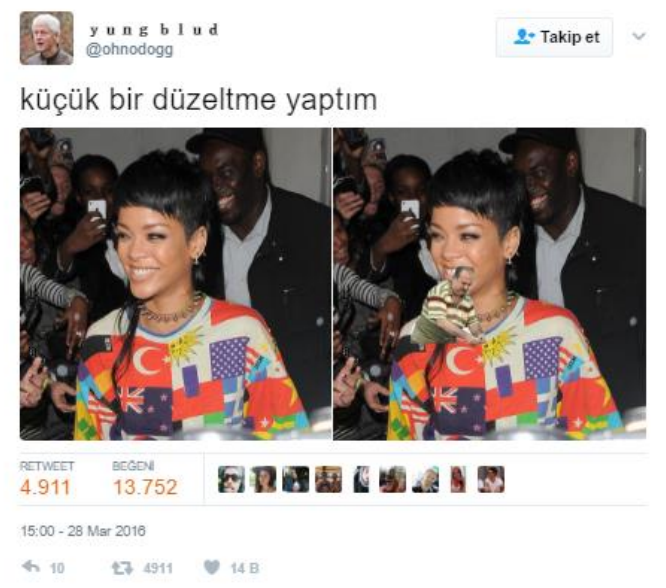

Troller, Türkiye gündemine bağlı olarak içerik üretmektedirler. Gündemde olan görseller farklı ve absürt konu başlıklarına içerik olmuştur. Bu görseller, trollerin yaratıcı ve mizahi dili ile oluşturulup Twitter'da dolaşıma sokulmuş kitleler tarafından beğeni ile karşılanmıştır. İlgi çeken bir fotoğraf veya video belli bir dil ile ayrı zamanlarda karşımıza Caps olarak çıkmaktadır. Yukarıdaki örnekte ise, @ohnodogg adlı trol, seçim dönemi balkonuna bayrak asan kişinin görselini absürt bir konu başlığı ile Rihanna'ya uyarlamış, 4.911 retweet, 13.752 beğeni almıştır.

Resim 8: Caps Örneği 8

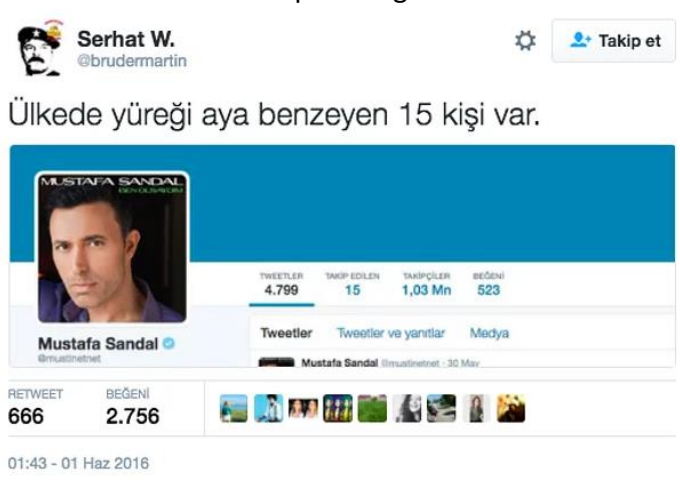

Troller, her zaman bulundukları zamana göre içerik üretmezler. Yaratıcı mizahları ile gördükleri herhangi bir olayı konuya ilişkin başka bir konu ile bağdaştırırlar. Twitter trollerinin bu yaratıcı içerik üretimine örnek olarak yukarıdaki Caps'i verebiliriz. Twitter trolü @brudermartin Mustafa Sandal'ın “Aya benzer yüreğim, e doğal olarak takipteyim" şarkısını yaratıcı bir bakış açısı ile Mustafa Sandal'ın Twitter'da takip ettiği kişilerle bağdaştırmıştır. Trolün attığı bu tweet dolaşıma sokulduktan sonra 666 retweet, 2.756 beğeni almıştır. 


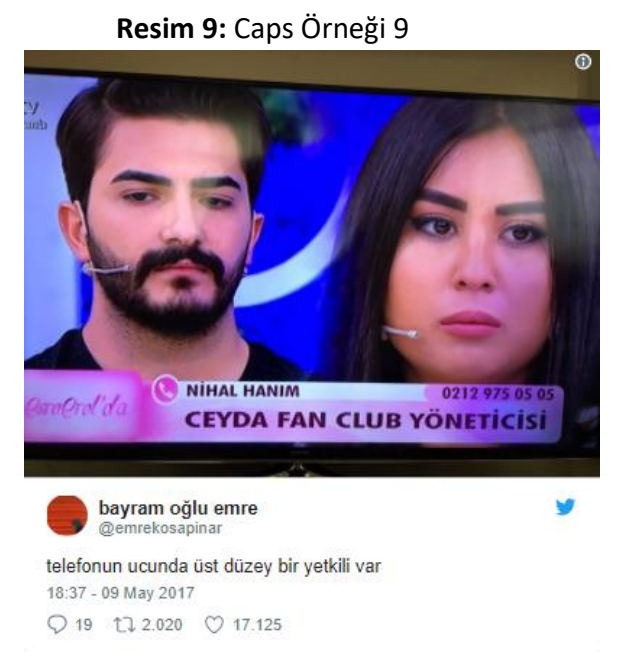

Trollerin içeriklerini oluştururken başvurdukları bir diğer ortam ise kitle iletişim araçlarıdır. Kitle iletişim araçlarından biri olan televizyon troller için büyük bir kaynaktır. Haberlerde yayınlanan komik görüntüler, dizi sahnelerinde geçen diyaloglar, canlı yayınlarda yaşananlar bir Caps'e konu olabilir. Twitter trollerinin televizyon içeriğini mizahi bir şekilde içerik üretimine "Ceyda Fan Club Yöneticisi" Caps'ini verebiliriz. Twitter trolü @emrekosapinar Esra Erol'un programına konuk olan Ceyda Hanım'ın sosyal medya mecralarındaki hayranlarının yönetici olan Nihal Hanım’ın bağlandığını görüp televizyonun görüntüsünü almış ve izleyicinin kendi ismi ile değil bir hayran olarak bağlanmasının daha ilgi çekici olduğunu, sosyal medyada aktif olduğunu belirten izleyiciyi alaycı bir ifade ile Caps'e dönüştürüp dolaşıma sunmuştur. Twitter'da paylaşılan bu içerik 2.020 retweet, 17.125 beğeni, 19 tane yorum almıştır.

Resim 10: Caps Örneği 10

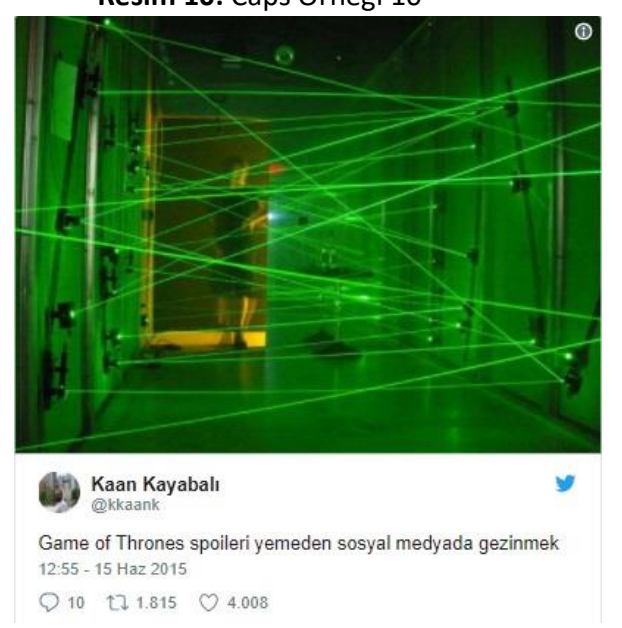

Yeni medyanın ve alışkanlıklarımızın değişmesi doğru orantılıdır. Eskiden kitle iletişim araçları ile izleyici konumundayken şimdi içerik üreten yaptıklarımızı, izlediklerimizi ve konularla ilgili düşüncelerimizi paylaşabildiğimiz alışkanlıklarımız mevcuttur. Son dönemde neredeyse bir çoğumuzun merakla takip ettiği Game of Thrones dizisinin yeni kazandığımız alışkanlıklardan biri olan sosyal medyada paylaşım, yorum yazma konusunun dizinin bölümleri ile ilgili bilgi vermesi konusunda şikayeti dile getiren bu Caps Kaan Kayabalı tarafından oluşturulmuştur. Caps'te en dikkat çeken şey ise bilgiye kolay ulaşılabilirliğin olumsuz yanı ve yeni kazandığımız alışkanlıkların doğru kullanılamamasıdır. Game of Thrones'un yeni bölümünü izleyenlerin güncel 
bir konu olması adına sürekli içerik paylaşması nedeniyle yeni bölümden haberdar olmayanların sosyal medyada çektiği zorluğu anlatan bu Caps 1.815 retweet, 4.008 beğeni, 10 tane yorum almıştır.

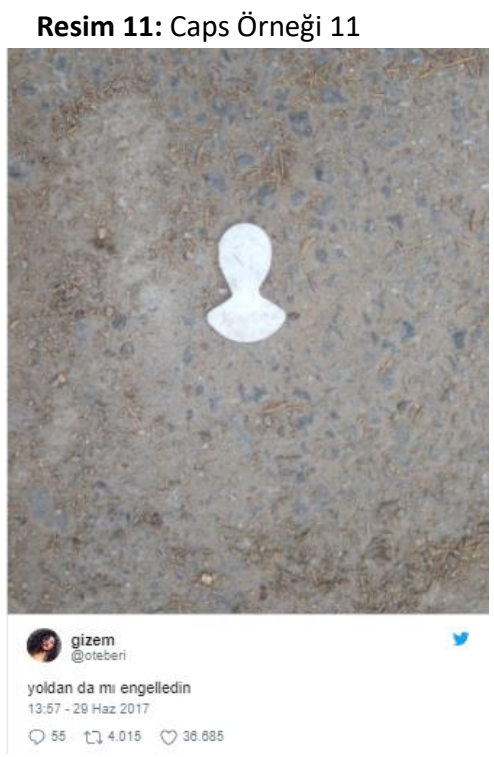

Caps içeriklerinin üretilmesi bazen zaman alırken bazen de gündelik olayları anında Caps'e çevrilmesi ile kısa sürede oluşturulup dolaşıma sokulur. Yeni medya ile kazandığımız bazı alışkanlıklarımız arkadaşlarımızla veya ikili ilişkilerimizde iletişim şeklimizi değiştirir. Troller sosyal medya ile değişen iletişim şekillerimizi mizahi bir şekilde ele alır ve izleyici paylaşır. Sosyal medya ile hayatımıza giren "engelleme" butonunun karşımızdaki kişi ile iletişime geçmeyi sıfıra indirmesine tepki gösteren trol hesaplardan biri @oteberi olmuştur. @oteberi yerde gördüğü engelleme görseli ile yeni alışkanlıklarımızı mizahi bir şekilde birleştirmiş ve Twitter'da dolaşıma sokmuştur. Paylaşılan bu Caps 4.015 retweet, 36.635 beğeni, 55 tane yorum almıştır.

Resim 12: Tweet Örneği 1

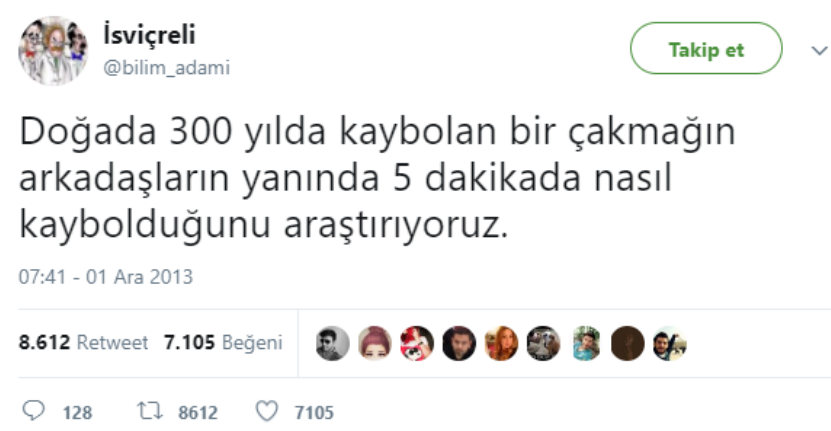

Mesleklerin medya aracılığı ile bize yansıtılan olumsuz, eksik, yetersiz tarafını konu alan trol hesapların en başında @bilim_adami gelmektedir. İsviçreli Bilim Adamı kendi Twitter sayfasında gündelik ve herkesin yaşadığı olaylara kendine has alaycı tavrı ile çözümler bulmaya yönelik içerikler oluşturmaktadır. Atılan bu Tweet'te görüldüğü gibi neredeyse her sigara kullanıcısının başına gelen çakmak kaybetme olayının çözümünü İsviçreli bilim adamları ile bağdaştırmıştır. Atılan bu Tweet 8.612 Retweet, 7.105 beğeni almıştır. 
Resim 13: Tweet Örneği 2

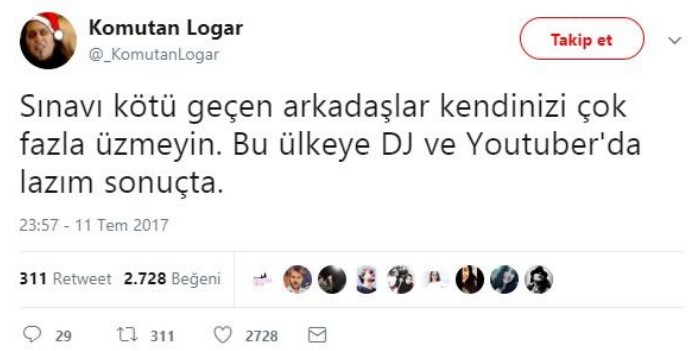

Trollerin en fazla içerik ürettiği konulardan biride sosyal medya mecralarını yetersiz içeriklerle doldurup tamamen maddi gelir sağlamaya çalışan bireylerdir. Komutan Logar isimli trol sınavda başarılı olamayan kişilerin çok fazla emek gerektirmediğini, herkesin yapabileceğini düşündüğü DJ ve Youtuberlık mesleğini seçebileceğini alaycı bir tavırla dile getirmiştir. Komutan Logar isimli trolün dolaşıma soktuğu bu Tweet 311 Retweet, 2.728 beğeni almıştır.

Resim 14: Tweet Örneği 3

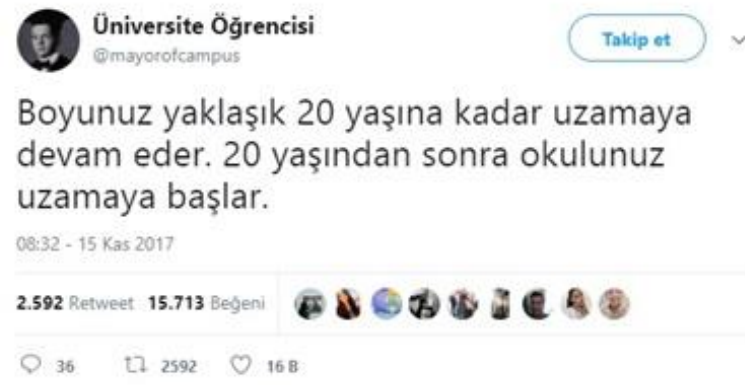

Trol hesapların bir kısmı içeriklerini oluştururken herkesin yaşadığı belli bir yaş aralığının deneyimlerini göz önünde bulundurur. O yaş aralığında herkesin deneyimlediği olayları ise mizahi bir dil ile içerik olarak kullanıcılarına sunar. Üniversite Öğrencisi isimli trol hesap bu hesaplardan biridir. Yukarıdaki Tweet'te ise üniversitede çoğu insanın yaşadığı okul ve boy uzatma deneyimini mizahi bir dil ile birleştirmiş ve dolaşıma sokmuştur. Atılan bu Tweet 2.592 Retweet, 15.713 beğeni almıştır.

Resim 15: Tweet Örneği 4

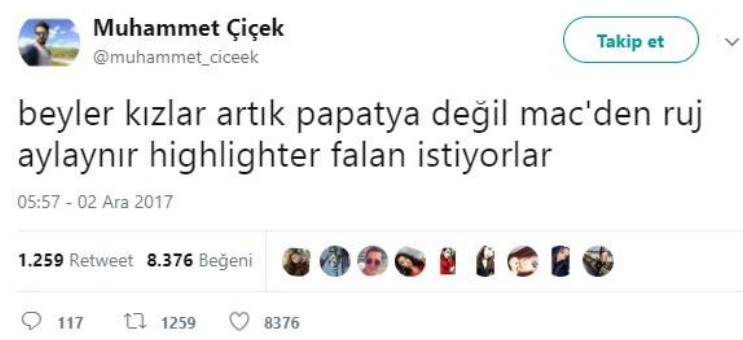

Youtube ve Instagram içeriklerinin çoğalması, kullanıcı sayısının giderek artmasıyla kadınlar ve erkekler birbirleriyle ilgili daha detaylı bilgiye erişiyor. Twitter trolü bu Tweet'inde sosyal medya ile iç içe olması nedeniyle kadınlara dair daha derin bilgiye ulaştığını mizahi olarak dile getiriyor. Kadınların sosyal medya 
yokken daha gösterişsiz şeyleri talep ettiğini sosyal medyanın hayatımıza girmesi ile taleplerinin ve alışkanlıklarının değiştiğini belirtiyor. Paylaşılan bu Tweet 1.259 Retweet 8.376 Beğeni almıştır.

Resim 16: Tweet Örneği 5

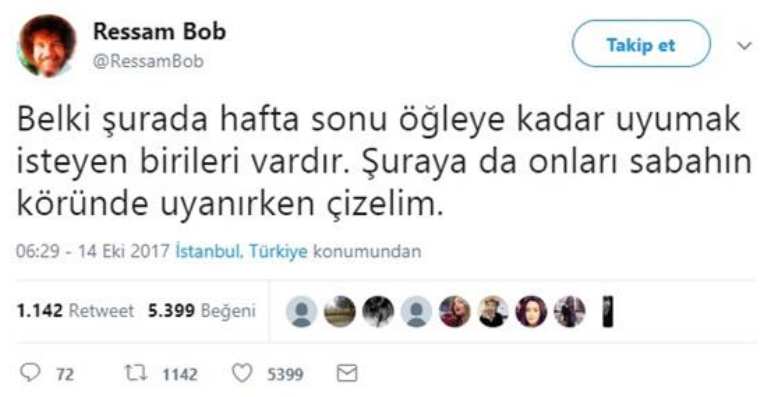

Troller herkesin tanıdığı ve sevdiği kişilerle ilgilide mizahi bir dil kullanarak içerek üretebilir. Bu tarza örnek olarak "Şimdi şuraya mutlu bir çalı çizelim" diyerek çalı fırçasını eline alan Bob Ross'un ağzından içerik üreten @RessamBob. Bu trol hesap gündemle veya gündelik hayatla ilgili içerikler oluşturuyor ve Bob Ross'un sıkça kullandığı kelimelerle Tweetlerini dolaşıma sokuyor. @RessamBob adlı trolün attığı bu Tweet 1.142 Retweet, 5.399 beğeni almıştır.

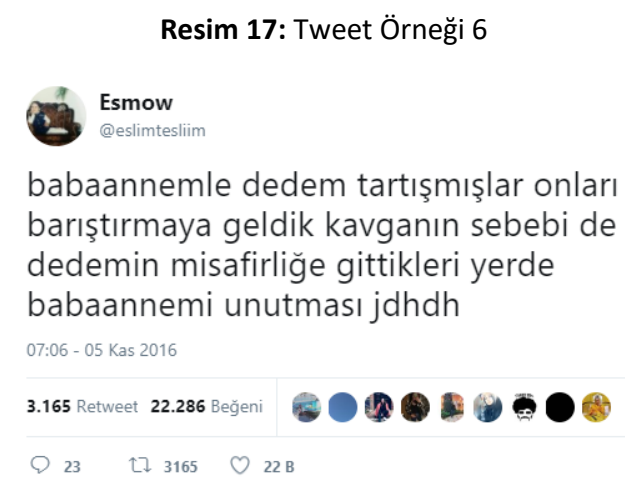

Twitter trolleri genellikle siyasi, magazinsel veya haber değeri olan içerikler üretmek yerine; günlük yaşamlarında kendilerini güldüren ve takipçilerini de güldürebilecek içerikler paylaşmaktadırlar. Bu içeriklerin herhangi bir mesajı veya amacı olmasına gerek yoktur. Komik ve gerçekten yaşanmış olabilecek konular üzerine yazılmış olması yeterlidir. Yukarıdaki örnekte @eslimteslim isimli trol, günlük hayatında yaşadığı veya yaşamış olabileceği komik bir deneyimi paylaşmıştır. Twitter aracılığıyla yayınladığı bu Tweet; 23 yorum, 3.165 Retweet ve 22.286 beğeni almıştır. 
Resim 18: Tweet Örneği 7

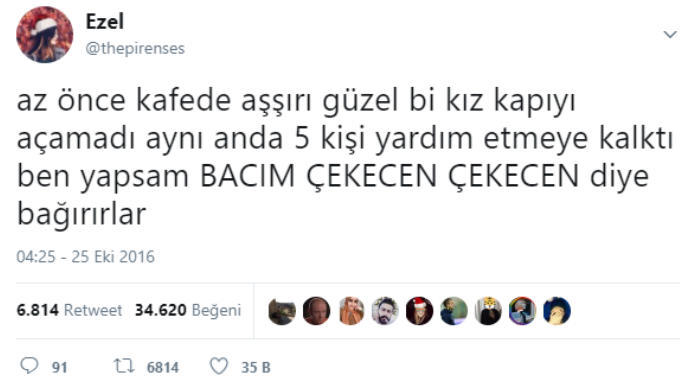

Trollerin popülerleşmesinin en önemli etkenlerinden biri, takipçilerini anlayarak onların dilinden konuşabilmeleridir. Troller hem üzerinde konuştukları konuları seçerken hem de yazım tarzlarını belirlerken takipçilerini en ön plana koymakta ve bu doğrultuda içeriklerini hazırlamaktadırlar. Bu davranış; bir komedyenin, izleyicilerine uygun bir dille, günlük yaşamdan farklı kesitleri anlatması ve onları güldürmeye çalışması gibi düşünülebilir. Yukarıdaki örnekte @thepirenses isimli trol, günlük yaşamında karşılaştığı bir olayı kendine özgün ve takipçilerine uygun bir dille anlatmış; Twitter üzerinde 91 yorum, 6.814 Retweet ve 34.620 beğeni almıştır.

Resim 19: Tweet Örneği 8

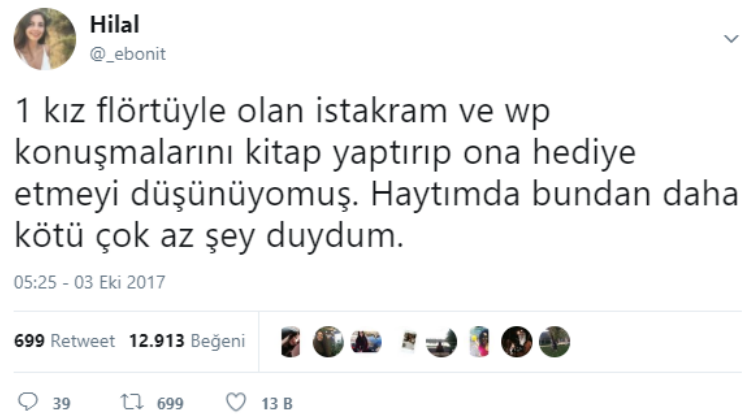

Bazı troller, ürettikleri içeriklerinde eleştirel bir dil kullanarak öne çıkmayı tercih etmektedirler. Farklı konular, kişiler veya günlük hayatlarındaki deneyimler eleştirilerinin bir parçası olabilmektedir. Bu eleştirilerde olumlu veya olumsuz herhangi bir amaç güdülmemektedir. Bu tarz içeriklerde önemli olan öncelikle komik bir konu üzerine yazabilmiş olmak, sonrasında ise diğer insanların da katılabileceği eleştiriler yapabilmektir. Yukarıdaki örnekte @_ebonit isimli Twitter trolü, başka bir bireye eleştirel bir şekilde yaklaşmış ve 39 yorum, 699 Retweet ve 12.913 beğeni almıştır. 
Resim 20: Tweet Örneği 9

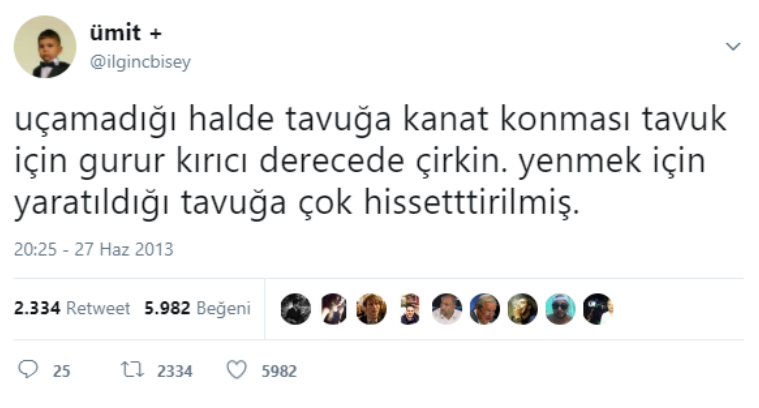

Twitter trollerinin özelliklerinden biri de absürt konulara mizahi bir dille yaklaşabilmeleridir. Troller, aslında birçok kişinin her gün gözlemlediği; fakat bu konu üzerine hiç düşünmediği içerikler üretebilmektedirler. Absürt içerikler üreten troller, herhangi bir konu ayrımı gözetmemektedirler. Yukarıdaki örnekte @ilgincbisey isimli kullanıcı, tavuklar ile ilgili absürt bir tespitte bulunmuştur. Tavukların kanatları olmasına rağmen uçamaması konusunda oluşturduğu bu içerikle, Twitter'da 25 yorum, 2.334 Retweet ve 5.982 beğeni almıştır.

Resim 21: Tweet Örneği 10

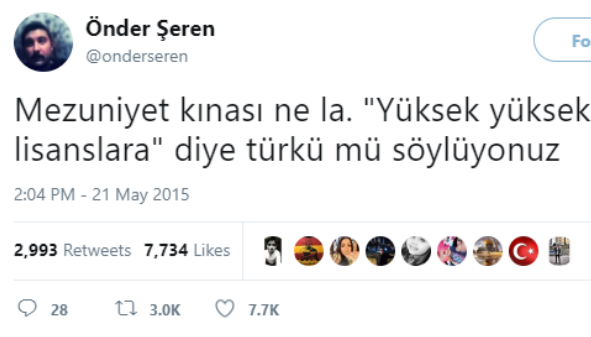

Twitter trollerinin en çok beslendiği konulardan biri kişilerin eğitim dönemleri ve bu dönemde yaşadıkları deneyimleri olmaktadır. Troller, kendi eğitim hayatlarında yaşadıkları veya başka insanlar tarafından aynı dönemde deneyimlenen herhangi bir konu üzerine içerik üretebilmektedirler. Troller tarafından mizahi ve kendilerine özgün dilleri ile üretilen içerikler, sosyal medyada özellikle öğrenci bireyler tarafından oldukça ilgi görmektedir. "Önder Şeren” isimli Twitter kullanıcısının, Türkiye'deki kültürümüze özgü bir eğitim dönemi deneyimini paylaşan ve kendine özgün diliyle yorumlanan yukarıdaki Tweet örnek olarak gösterilebilir. Bu örnek Tweet, Twitter'da 28 yorum, 2.993 Retweet ve 7.734 beğeni almıştır.

\section{Sonuç}

Yapılan çalışma sonucunda, yeni medyada mizahi ve yaratıcı dili ustaca kullanan trollerin, hedef kitlesinin gençler olduğu ve katılımcı kültürün gelişmesinde etkili oldukları söylenebilir. Zaman içerisinde teknolojinin gelişmesi ile okuma ve yazma etkinliği değişime uğramış; yeni medya ile birlikte okuma yazma alışkanlıkları çeşitlenmeye devam etmiştir. Türkiye'deki sosyal medya mecralarından Twitter, içerik üretimi ortamında hem kışkırtıcı hem de eğlenceli içerik oluşturulduğu için kitlelerin dikkatini çekmektedir. İçeriklerde kullanılan görsellerin, yaratıcı dil ve mizah ile birleştirilip dolaşıma sokulduğunda binlerce izleyiciyi olumlu veya olumsuz etkileyebileceğini görmekteyiz. Her Twitter trolü, kendine özgü mizahi ve yaratıcı dil yeteneği ile, farklı olayları aynı görsel üzerinde farklı mesajlar doğrultusunda kitlelere iletmekte ve izleyicilere farklı bakış açısı sunmaktadır. Twitter trolleri duygu, düşünce ve muhalif bakış açılarını Capsler üzerinden ortaya koymaktadır. Trollerin Caps üretimi dinamik bir yapıdadır. İzleyicilerin de sosyal mecralar üzerinden paylaşım yapması ile bu 
Capsler büyük bir kitleye yayılmaktadır. Gündelik hayatta, her alanda meydana gelen olaylar ile ilgili oluşturulan Capsler izleyicilerin konu üzerinde düşünmesini ve sorgulayıcı olmasını sağlamaktadır.

\section{Kaynakça}

Altunay, C. M. (2010). Twitter: Gündelik yaşamın yeni rutini "PIt Pıt Net". iletişim, 12, 31-56.

Bat, M. ve Vural, Z.B.A. (2014). Yeni Bir Medya Olarak Sosyal Medyanın Çerçevesi. (Ed. Z.B.Akıncı Vural), Dijital Panorama. Ankara: Ütopya.

Bruns, A. ve Bahnisch, M. (2009, Mart). Social Media: Tools for User-Generated Content Social Drivers Behind Growing Consumer Participation in User-Led Content Generation. State of the Art Volume: 1. http://www.smartservicescrc.com.au/files/files/Social_Media_State_of_the\%20Art_March2009.pdf internet adresinden 5 Mart, 2017 tarihinde edinilmiştir.

Burman, E. ve Parker, I. (1993). Discourse Analytic Research: Repertoires and Readings of Texts in Action. London: Routledge.

Derya Yücel, Yeni Medya Sanatı ve Yeni Müze, İstanbul,2012.s.76

Dovey J., Giddings S., Grant I., Kelly K. ve Lister M. (2009). New Media: A Critical Introduction Second Edition. New York: Routledge.

Et restoranı sahibi Nusret, ABD'de 'caps' oldu. (2017, 9 Ocak). Habercem. http://habercem.com/et-restoranisahibi-nusret-abd-de-caps-oldu_d139440.html internet adresinden 7 Mart, 2017 tarihinde edinilmiştir.

Greenhow, C. (2009). Tapping the Wealth of Social Networks for Professional Development. Learning \& Leading with Technology, 36(8), 10-11.

Hardaker, C. (2013). Uh.... not to be nitpicky, but... the past tense of drag is dragged, not drug. Journal of Language Aggression and Conflict, 1(1), 58-86.

Jakubowicz,Karol. A new Notion of media. Reykjavik: Council of Europe, 2009

Kullar, U ve İnci, S. (2015). Inci Caps 'Kutsal Mizah Kırbacı'. İstanbul: Epsilon Yayınclık.

Langenscheidt (2010). Handwörterbuch Englisch. Berlin: Langenscheidt.

Manovich, Lev. (2001). The Language of New Media. Londra: The MIT Press Cambridge.

McLuhan, Marshall. Gutenberg Galaksisi, ìstanbul, Yapı Kredi Yayınları,2014

Nusret Amerika'yı da salladı (2017, 9 Ocak). CNN Türk. http://www.cnnturk.com/spor/nba/nusret-amerikayida-salladi internet adresinden 10 Mart, 2017 tarihinde edinilmiştir.

O'Reilly, T. ve Milstein, S. (2009). The Twitter Book. Sebastopol: O'Reilly Media.

Özsoy, D. (2015). Tweeting political fear: Trolls in Turkey. Journal of History School (JOHS), 12, 535-552.

Potter, J. ve Wetherell, M. (1987). Discourse and Social Psychology: Beyond Attitudes and Beliefs. London: Sage.

Taiwo, R. (2014). Impoliteness in online forums: A study of trolling in Nairaland. Chiluwa, P. Ifukor, R. Taiwo

(Edt.), Pragmatics of Nigerian English in Digital Discourse içinde (s. 67-76). Münih: Lincom Europa.

Vural, Z. B., \& Bat, M. (2010). Yeni Bir İletişim Ortamı Olarak Sosyal Medya: Ege Üniversitesi İletişim Fakültesine Yönelik Bir Araştırma. Journal Of Yasar University, 3348 - 3382 